\title{
The Effect of p53 Status on Radio-Sensitivity of Quiescent Tumor Cell Population Irradiated With $y$-Rays at Various Dose Rates
}

\author{
Shin-ichiro Masunaga ${ }^{a}$ e , Junya Kobayashi ${ }^{b}, K^{2}$ eizo Tano ${ }^{\text {a }}$, Yu Sanada ${ }^{a}$, \\ Minoru Suzukic, Koji Ono ${ }^{\mathrm{d}}$
}

\begin{abstract}
Background: The aim of the study was to clarify the effect of $p 53$ status of tumor cells on radio-sensitivity of solid tumors following $\gamma$-ray irradiation at various dose rates, referring to the response of intratumor quiescent $(\mathrm{Q})$ cells.

Methods: Human head and neck squamous cell carcinoma cells transfected with mutant TP53 (SAS/mp53) or with neo vector (SAS/neo) were injected subcutaneously into hind legs of nude mice. Tumor bearing mice received 5-bromo-2'-deoxyuridine (BrdU) continuously to label all intratumor proliferating $(\mathrm{P})$ cells. They received $\gamma$-rays at a high, middle or low dose rate. Immediately or $9 \mathrm{~h}$ after the high doserate irradiation (HDR, $2.5 \mathrm{~Gy} / \mathrm{min}$ ), or immediately after the middle (MDR, $0.039 \mathrm{~Gy} / \mathrm{min}$ ) or low (LDR, $0.00098 \mathrm{~Gy} / \mathrm{min}$ ) dose-rate irradiation, the tumor cells were isolated and incubated with a cytokinesis blocker, and the micronucleus (MN) frequency in cells without BrdU labeling ( $Q$ cells) was determined using immunofluorescence staining for BrdU.
\end{abstract}

Results: Following $\gamma$-ray irradiation, SAS/neo tumor cells, especially intratumor Q cells, showed a marked reduction in sensitivity due to the recovery from radiation-induced damage, compared with the total or Q cells within SAS/mp53 tumors that showed little repair capacity. The recovery capacities following $\gamma$-ray irradiation were greater in $\mathrm{Q}$ than total cell population and increased in the following order of $9 \mathrm{~h}$

Manuscript submitted August 30, 2018, accepted September 10, 2018

aParticle Radiation Biology, Institute for Integrated Radiation and Nuclear Science, Kyoto University, 2-1010, Asashiro-nishi, Kumatori-cho, Sennan-gun, Osaka 590-0494, Japan

${ }^{\mathrm{b}}$ Genome Repair Dynamics, Radiation Biology Center, Kyoto University, Yoshida-Konoe-cho, Sakyo-ku, Kyoto 606-8501, Japan

cParticle Radiation Oncology, Institute for Integrated Radiation and Nuclear Science, Kyoto University, 2-1010, Asashiro-nishi, Kumatori-cho, Sennangun, Osaka 590-0494, Japan

${ }^{\mathrm{d}}$ Kansai BNCT Collaborative Research Center, Osaka Medical College, 2-7, Daigaku-cho, Takatsuki, Osaka 569-8686, Japan

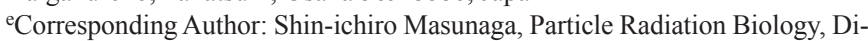
vision of Radiation Life Science, Institute for Integrated Radiation and Nuclear Science, Kyoto University, 2-1010, Asashiro-nishi, Kumatori-cho, Sennangun, Osaka 590-0494, Japan. Email: masunaga.shinichiro.6m@kyoto-u.jp

doi: https://doi.org/10.14740/jocmr3610w after $\mathrm{HDR}<\mathrm{MDR}<\mathrm{LDR}$. Thus, the difference in radio-sensitivity between the total $(\mathrm{P}+\mathrm{Q})$ and $\mathrm{Q}$ cells after $\gamma$-ray irradiation increased in the same order.

Conclusion: To secure controlling solid tumors as a whole, difference in sensitivity between total and Q tumor cells especially in solid tumors irrespective of $p 53$ status has to be suppressed as irradiation dose rate decreases, for instance, through employing combined method for enhancing the response of Q tumor cells.

Keywords: $p 53$ status; Quiescent cell; $\gamma$-rays; Irradiation dose rate; Recovery from radiation-induced damage

\section{Introduction}

It was shown that the $p 53$ tumor suppressor gene serves a critical role in maintaining genomic stability during the cell cycle checkpoint in G1 and G2/M transition, and as an effector of DNA repair and apoptosis $[1,2]$. Wild-type $p 53$ is needed to activate apoptosis in sensitive cells in response to DNA damage $[1,2]$. These actions of $p 53$ are potentially critical in determining the effectiveness of ionizing radiation and/or chemotherapeutic agents. $p 53$ is mutated in a majority of human solid tumors and plays a central role in the cellular response to DNA-damaging treatments like ionizing radiation, chemotherapy or hypoxic stress [3]. Hypoxic stress also induces $p 53$ protein accumulation and p53-dependent apoptosis, but does not induce $p 53$-dependent cell cycle arrest [3]. Loss of $p 53$ function may result in resistance to DNA-damaging agents, including ionizing radiation and hypoxic stress $[1,3]$. Actually, mutations in the $p 53$ tumor suppressor gene have an impact on the clinical course of several human cancers: patients with cancers harboring $p 53$ mutations often have a worse prognosis than those with tumors harboring wild-type $p 53[1,3]$. Thus, the genetic and functional status of the $p 53$ gene is an important factor in guiding therapeutic strategies for cancer patients.

Meanwhile, intensity modulated radiotherapy (IMRT) and stereotactic irradiation have come into common usage as radiotherapy techniques for treating malignancies. Both modalities generally use multiple arc or fixed-portal radiation beams, and radiation beams are exposed intermittently. These techniques 
often require $30 \mathrm{~min}$ or longer in one treatment session for precise positioning of patients $[4,5]$. Prolongation of irradiation time may reduce a radiation effect and evokes a major concern for the dose rate effect. Thus, it is needed to clarify the effect of the reduction of dose rate on the radio-sensitivity of tumors in vivo.

When using low linear energy transfer (LET) radiation, lowering the dose rate is thought to reduce late effects in normal tissue much more than it decreases tumor control. Thus, the "therapeutic ratio" increases as the dose rate decreases because the therapeutic ratio is equal to the ratio of tumor control to normal tissue complications. Furthermore, the difference between early and late effects for low dose-rate radiotherapy, as well as improving the therapeutic ratio, allows complete treatment in a short period of time, minimizing the effects of tumor repopulation. In other words, decreasing the dose rate increases the therapeutic ratio, limited only by tumor cell repopulation [6]. This is the primary rationale for low dose-rate radiotherapy using low-LET radiation.

On the other hand, many cells in solid tumors are quiescent in situ but still clonogenic [7]. The quiescent (Q) tumor cells are more resistant to low-LET radiation because of their larger hypoxic fraction and greater capacity to recover from potentially lethal damage (PLD) than proliferating (P) tumor cells. In addition, the rationale for low dose-rate radiotherapy does not take into account the response of $\mathrm{Q}$ intratumor cells at all.

In this study, we examined the characteristics of radiosensitivity in the total $(\mathrm{P}+\mathrm{Q})$ and $\mathrm{Q}$ cell populations in solid tumors irradiated with irradiation with ${ }^{60} \mathrm{Co}$ or ${ }^{137} \mathrm{Cs} \gamma$-rays at various dose rates from very low to high dose rate. The responses of the total $(=\mathrm{P}+\mathrm{Q})$ and $\mathrm{Q}$-cell populations in irradiated solid tumors were separately detected with the method for selectively detecting the response of Q cells in solid tumors [8], using two different tumor cell lines with identical genetic backgrounds except for $p 53$ status.

\section{Materials and Methods}

\section{Cells, tumors and mice}

The human head and neck squamous cell carcinoma cell line SAS (JCRB, Tokyo, Japan) was cultured at $37{ }^{\circ} \mathrm{C}$ in Dulbecco's modified Eagle's medium (DMEM) containing 20 $\mathrm{mM}$ 2-[4-(2-hydroxyethyl)-1-piperazinyl]ethanesulfonic acid (HEPES) and $12.5 \%$ fetal bovine serum in a conventional humidified $5 \% \mathrm{CO}_{2}$ incubator. SAS cells show the phenotype of wild-type $p 53$ in radiation- and heat-induced signal transduction $[9,10]$. Plasmid pC53-248, which contains an mp53 gene (codon 248, from Arg to Trp) producing a dominant negative mp53 protein, and plasmid pCMV-Neo-Bam, which contains a neo-resistance marker, were provided by B. Vogelstein (Johns Hopkins Oncology Center, Baltimore, MD, USA). These plasmids were linearized with HindIII. Confluent SAS cells, approximately $2 \times 10^{6}$ cells in a $75-\mathrm{cm}^{2}$ flask, were trypsinized, and the resulting cell suspension in phosphate-buffered saline (PBS) $(1 \mathrm{~mL})$ was transferred into an electroporation chamber.
Cells were supplemented with linearized DNA $(10 \mu \mathrm{g} / 10 \mu \mathrm{L}$ of pC53-248 or pCMV-Neo-Bam) and electroporated three times at $600 \mathrm{~V}$. After standing for $30 \mathrm{~min}$ at room temperature, cells were plated onto dishes $10 \mathrm{~cm}$ in diameter in DMEM and incubated at $37^{\circ} \mathrm{C}$. Forty-eight hours later, cells were treated with G418 (geneticin, $200 \mu \mathrm{g} / \mathrm{mL}$; Sigma Chemical Co., St Louis, MO, USA), an agent for selection of transfected clones, and then incubated at $37^{\circ} \mathrm{C}$ for 14 days to allow colony formation. Colonies resistant to G418 were isolated with cloning cylinders. Through these manipulations, two stable transfectants $\mathrm{SAS} / m p 53$ and SAS/neo were established. SAS/neo cells have a functionally wild-type $p 53$ protein, and SAS/mp53 cells express a dominant-negative $p 53$ protein. The procedure used for transfection is described in detail elsewhere [9, 10].

Cells were collected from exponentially growing cultures, and approximately $5.0 \times 10^{5}$ cells were inoculated subcutaneously into both hind legs of 6- to 7-week-old syngeneic female $\mathrm{Balb} / \mathrm{cA}$ nude mice. Three weeks after inoculation, a tumor with a diameter of approximately $7 \mathrm{~mm}$ could be observed at each implanted site, whichever stable transfectant was used.

Meanwhile, in locally advanced or recurrent head and neck tumors, especially which are refractory to conventional cancer therapy including radiation therapy using low LET radiation X-rays, p53 status of the tumor cells is often mutated and the tumors often show hypoxic tendency rather than fresh and non-treated virgin tumors $[11,12]$.

\section{Labeling with 5-bromo-2'-deoxyuridine (BrdU)}

Two weeks after tumor cell inoculation, mini-osmotic pumps (Durect Corporation, Cupertino, CA, USA) containing BrdU dissolved in physiological saline $(250 \mathrm{mg} / \mathrm{mL})$ were implanted subcutaneously to label all $\mathrm{P}$ cells for 7 days. Administration of BrdU did not change the tumor growth rate. The tumors were approximately $7 \mathrm{~mm}$ in diameter on treatment. The labeling index (LI) after continuous labeling with BrdU was 48.4\% (41.7-55.1\%) (mean (95\% confidence limit)) and 43.2\% (37.0$49.4 \%$ ) for SAS/neo and SAS/mp53 tumor cells, respectively, and reached a plateau level at these stages. Therefore, in this study, we regarded tumor cells not incorporating BrdU after continuous labeling as Q cells.

\section{Irradiation}

After labeling with BrdU, the tumor-bearing mice underwent $\gamma$-ray irradiation. The irradiation was performed with the tumor-bearing mice held in a specially designed device made of acrylic resin with the tail or both arms and legs firmly fixed with an adhesive tape, without anesthesia.

$\gamma$-ray irradiation was performed with a ${ }^{6} \mathrm{Co} \gamma$-ray irradiator available at Institute for Integrated Radiation and Nuclear Science, Kyoto University at a dose rate of $2.5 \mathrm{~Gy} / \mathrm{min}$, such as conventionally used for high dose-rate irradiation (HDR). Middle dose-rate irradiation (MDR) was performed at a dose rate of $0.039 \mathrm{~Gy} / \mathrm{min}$ by maintaining an appropriate distance between the ${ }^{6 \circ} \mathrm{Co}$ radiation source and the irradiated tumorbearing mouse fixed within the specially constructed device. 
Meanwhile, low dose-rate irradiation (LDR) was carried out using ${ }^{137} \mathrm{Cs} \gamma$-ray irradiator with a source of $1,850 \mathrm{GBq}$ at a dose rate of $0.00098 \mathrm{~Gy} / \mathrm{min}$ also through maintaining an appropriate distance between the radiation source and the irradiated tumor-bearing mouse at Radiation Biology Center, Kyoto University.

According to the International Commission on Radiation Units and Measurements Report 58 concerning dosimetry in intracavitary brachytherapy for uterine cancer, high, middle and low dose-rate irradiation is defined as $>0.2 \mathrm{~Gy} / \mathrm{min}(12$ $\mathrm{Gy} / \mathrm{h}), 0.033$ - $0.2 \mathrm{~Gy} / \mathrm{min}(2-12 \mathrm{~Gy} / \mathrm{h})$ and $<0.033 \mathrm{~Gy} / \mathrm{min}$ $(2 \mathrm{~Gy} / \mathrm{h})$, respectively [13]. Based on this criterion, the HDR, MDR and LDR used in the present study fit with the high doserate, middle dose-rate and low dose-rate irradiation, respectively.

Each irradiation group also included mice that had not been pretreated with BrdU. The tumors were then excised immediately or $9 \mathrm{~h}$ after irradiation.

\section{Immunofluorescence staining of BrdU-labeled cells and observation of micronucleus (MN) formation}

The tumors were excised from mice given BrdU, minced, and trypsinized $(0.05 \%$ trypsin and $0.02 \%$ ethylenediaminetetraacetic acid (EDTA) in PBS at $37^{\circ} \mathrm{C}$ for $15 \mathrm{~min}$ ). The tumor cell suspensions were incubated for $48 \mathrm{~h}$ in tissue culture dishes containing complete medium and $1.0 \mu \mathrm{g} / \mathrm{mL}$ of cytochalasin-B to inhibit cytokinesis while allowing nuclear division, and the cultures were then trypsinized and cell suspensions were fixed. After the centrifugation of fixed cell suspensions, the cell pellet was resuspended with cold Carnoy's fixative. The suspension was then placed on a glass microscope slide and the sample was dried at room temperature. The slides were treated with $2 \mathrm{M}$ hydrochloric acid for $45 \mathrm{~min}$ at room temperature to dissociate the histones and partially denature the DNA. The slides were then immersed in borax-borate buffer $(\mathrm{pH} 8.5)$ to neutralize the acid. BrdU-labeled tumor cells were detected by indirect immunofluorescence staining using monoclonal antiBrdU antibody (Becton Dickinson, San Jose, CA, USA) and fluorescein isothiocyanate (FITC)-conjugated antimouse immunoglobulin G (whole molecule) antibody (Sigma, St Louis, MO, USA). To observe double staining of tumor cells with green-emitting FITC and red-emitting propidium iodide (PI), cells on the slides were treated with PI and monitored under a fluorescence microscope.

The MN frequency in BrdU-unlabeled cells ( $\mathrm{Q}$ cells at irradiation) could be examined by counting the micronuclei in the binuclear cells that showed only red fluorescence. The MN frequency was defined as the ratio of the number of micronuclei in the binuclear cells to the total number of binuclear cells observed [8].

The ratios obtained in tumors not pretreated with BrdU indicated the $\mathrm{MN}$ frequency at all phases in the total $(\mathrm{P}+\mathrm{Q})$ tumor cell populations. More than 300 tumor cells and binuclear cells were counted to determine the apoptosis frequency and the MN frequency, respectively.

Needless to say, the induction of an $\mathrm{MN}$ requires division of the cell nucleus [14]. The duration of incubation with cytochalasin-B allowed Q cells to be recruited into the cell cycle. Thus, the optimal incubation period was determined so that the maximum rate of binuclear tumor cells could be observed. The frequencies of MN for BrdU-labeled cells were modified because the radiosensitization effect of the incorporated BrdU could potentially influence the frequencies in BrdU-labeled cells. Thus, the correct frequencies of BrdU-labeled cells without the BrdU effect are not able to be determined. During continuous labeling with BrdU, the shift of cells from $\mathrm{P}$ to $\mathrm{Q}$ population could result in labeled Q cells. These cells were excluded when we scored micronuclei in binuclear cells in tumor cells showing only red fluorescence by PI for DNA staining, because these cells were stained with FITC.

\section{Cell survival assay}

The cell survival assay was also performed in mice given no BrdU using an in vivo-in vitro assay method. Tumors were disaggregated by stirring for $20 \mathrm{~min}$ at $37{ }^{\circ} \mathrm{C}$ in $\mathrm{PBS}$ containing $0.05 \%$ trypsin and $0.02 \%$ EDTA. The cell yield was $1.5(1.2$ $-1.8) \times 10^{7} / \mathrm{g}$ and $3.4(2.6-4.2) \times 10^{6} / \mathrm{g}$ for SAS/neo and SAS/ mp53 tumors, respectively.

To confirm the stability of transfectants SAS/neo and $\mathrm{SAS} / m p 53$, part of the tumor cell suspensions obtained after irradiation and tumor cells from part of the colonies grown through the in vivo-in vitro assay method were subjected to western blotting analysis for $p 53$ and Bax proteins as described by Ota et al [15]. Not only the level, but also the function of p53 protein could be detected because the bax gene is a target of the $p 53$ gene. As a result, it was confirmed that the $p 53$ status of each transfectant was not changed by these experimental procedures. Three mice were used to assess each set of conditions and each experiment was repeated three times. To examine the differences between pairs of values, Student's $t$-test was used when variances of the two groups could be assumed to be equal; otherwise the Welch $t$-test was used. $P$ values were from two-sided tests.

\section{Results}

Table 1 shows the plating efficiencies for the total tumor cell population and the $\mathrm{MN}$ frequencies without radiation for the total and Q cell populations in each tumor. Overall, SAS/mp53 tumor cells showed significantly lower plating efficiency in the total cell populations and significantly higher $\mathrm{MN}$ frequencies in both the total and $\mathrm{Q}$ cell populations $(\mathrm{P}<0.05)$ than $\mathrm{SAS} /$ neo tumor cells. Further, Q cells showed significantly higher $\mathrm{MN}$ frequencies than the total cell population under each set of conditions in each tumor $(\mathrm{P}<0.05)$.

The clonogenic cell survival curves for total tumor cell populations immediately and $9 \mathrm{~h}$ after $\gamma$-ray irradiation with HDR and immediately after $\gamma$-ray irradiation with MDR and LDR are shown in Figure 1. On the whole, SAS/mp53 tumor cells were more radioresistant than SAS/neo tumor cells except under LDR. The increase in the surviving fraction (SF) 
Table 1. Plating Efficiency and Micronucleus Frequency at 0 Gy

\begin{tabular}{|c|c|c|}
\hline & Total tumor cells & Quiescent cells \\
\hline \multicolumn{3}{|l|}{$\mathrm{SAS} /$ neo } \\
\hline Plating efficiency (\%) & $45.5 \pm 8.9^{\mathrm{a}}$ & \\
\hline Micronucleus frequency & $0.038 \pm 0.006$ & $0.056 \pm 0.007$ \\
\hline \multicolumn{3}{|l|}{$\mathrm{SAS} / m p 53$} \\
\hline Plating efficiency $(\%)$ & $23.5 \pm 4.1$ & \\
\hline Micronucleus frequency & $0.072 \pm 0.008$ & $0.111 \pm 0.010$ \\
\hline
\end{tabular}

aMean \pm standard error $(n=6)$.

with the 9-h delayed assay, that is, PLDR, and the increase in the SF after MDR or LDR were observed more clearly in $\mathrm{SAS} /$ neo than in SAS/mp53.

The net micronucleus frequencies for total and Q-cell populations immediately and $9 \mathrm{~h}$ after $\gamma$-ray irradiation with HDR and immediately after $\gamma$-ray irradiation with MDR and LDR are shown in Figure 2. For baseline correction, we used the net $\mathrm{MN}$ frequency to exclude the $\mathrm{MN}$ frequency in non-irradiated control tumors. The net $\mathrm{MN}$ frequency was the $\mathrm{MN}$ frequency in the irradiated tumors minus that in the non-irradiated tumors. On the whole, Q tumor cells were more radioresistant than the total tumor cell population. The decrease in the net $\mathrm{MN}$ frequency with the 9-h delayed assay and the decrease in the net MN frequency after MDR or LDR were more obvious in SAS/neo and Q cells than in SAS/mp53 and the total cell population, respectively.

To evaluate the recovery capacity from the damage induced by HDR or during MDR or LDR in total and Q-cell populations within these two tumors, dose modifying factors were calculated in both cell populations at various endpoints using the data given in Figures 1 and 2 (Table 2). Overall, regardless

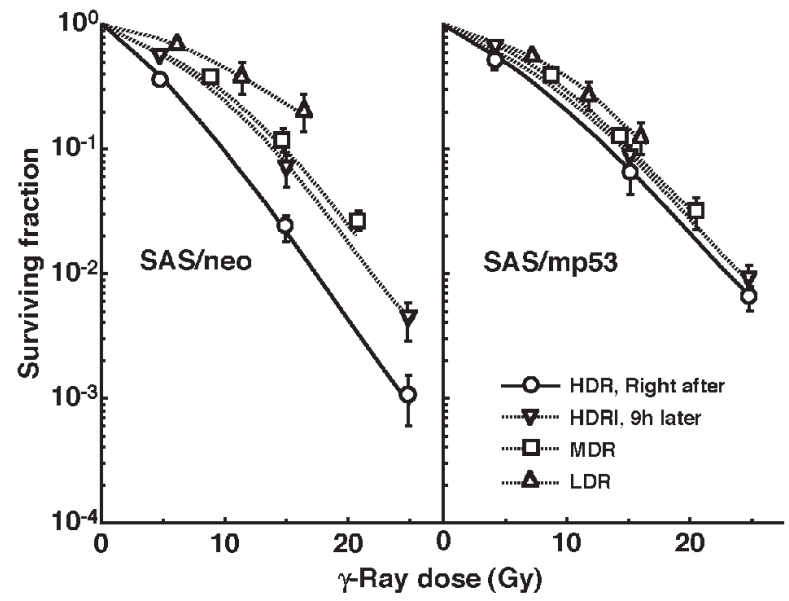

Figure 1. Surviving fractions following $y$-ray irradiation. The clonogenic cell survival curves for total tumor cell populations immediately and $9 \mathrm{~h}$ after $\mathrm{y}$-ray irradiation with high dose-rate irradiation (HDR) and immediately after $\gamma$-ray irradiation with middle dose-rate irradiation (MDR) and low dose-rate irradiation (LDR) are shown. The left and right panels show SAS/neo and SAS/mp53 tumor cells, respectively. Bars represent standard errors $(n=6)$.

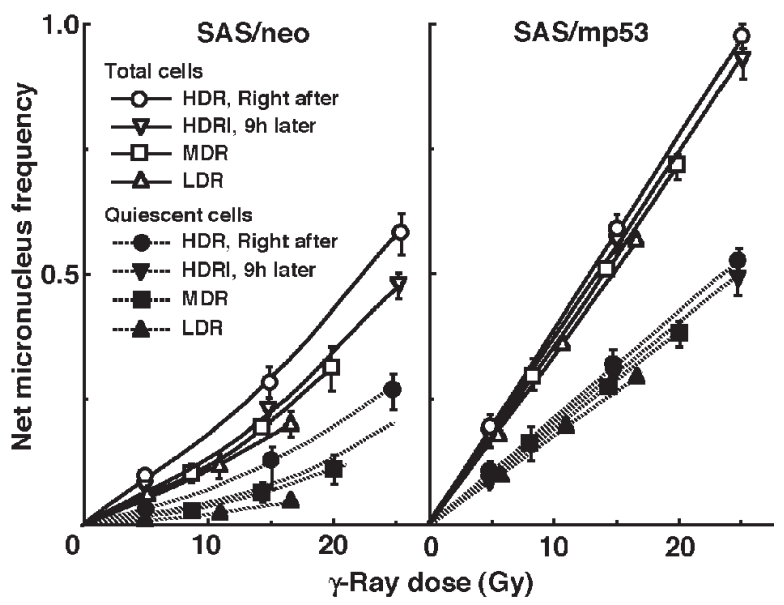

Figure 2. Net micronucleus frequencies following y-ray irradiation. The net micronucleus frequencies for total (solid lines, open symbols) and quiescent (dotted lines, solid symbols) cell populations immediately and $9 \mathrm{~h}$ after $\mathrm{y}$-ray irradiation with high dose-rate irradiation (HDR) and immediately after $\gamma$-ray irradiation with middle dose-rate irradiation (MDR) and low dose-rate irradiation (LDR) are shown. The left and right panels show SAS/neo and SAS/mp53 tumor cells, respectively. Bars represent standard errors $(n=6)$.

of the cell populations, SAS/mp53 tumor cells showed little recovery capacity under any irradiation conditions. In SAS/neo tumor cells, whether $9 \mathrm{~h}$ after HDRI or after MDR or LDR, the recovery capacities following $\gamma$-ray irradiation were significantly greater in Q-cell populations than total cell populations $(\mathrm{P}<0.05)$. In these two tumors, the recovery capacities in both total and Q tumor cell populations following $\gamma$-ray irradiation increased in the following order of $9 \mathrm{~h}$ after $\mathrm{HDR}<\mathrm{MDR}<$ LDR.

To compare the cell survival curve between these two tumor cells, we calculated the dose ratios for SAS/mp53 tumor

Table 2. Dose-Modifying Factors Due to a Delayed Assay or Reduced Irradiation Dose Rate ${ }^{a}$

\begin{tabular}{|c|c|c|c|}
\hline & HDR & MDR & LDR \\
\hline & \multicolumn{3}{|l|}{ 9h latser } \\
\hline \multicolumn{4}{|c|}{ Surviving fraction $=0.2$} \\
\hline $\mathrm{SAS} /$ neo & $1.5 \pm 0.15^{\mathrm{b}}$ & $1.6 \pm 0.15$ & $2.1 \pm 0.2$ \\
\hline $\mathrm{SAS} / m p 53$ & $1.1 \pm 0.1$ & $1.2 \pm 0.1$ & $1.3 \pm 0.1$ \\
\hline \multicolumn{4}{|c|}{ Net micronucleus frequency $=0.1$} \\
\hline \multicolumn{4}{|c|}{ Total tumor cells } \\
\hline $\mathrm{SAS} /$ neo & $1.4 \pm 0.1$ & $1.45 \pm 0.1$ & $1.8 \pm 0.15$ \\
\hline $\mathrm{SAS} / m p 53$ & $1.05 \pm 0.1$ & $1.1 \pm 0.1$ & $1.15 \pm 0.1$ \\
\hline \multicolumn{4}{|l|}{ Quiescent cells } \\
\hline SAS/neo & $1.55 \pm 0.15$ & $1.65 \pm 0.15$ & $1.85 \pm 0.2$ \\
\hline $\mathrm{SAS} / m p 53$ & $1.05 \pm 0.1$ & $1.1 \pm 0.1$ & $1.2 \pm 0.1$ \\
\hline
\end{tabular}

aThe ratio of the dose of radiation necessary to obtain each end-point with a delayed assay or reduced dose-rate irradiation to that needed to obtain each end-point with an assay immediately after high dose-rate irradiation. ${ }^{b}$ Mean \pm standard error $(n=6)$. 
Table 3. Dose-Modifying Factors for SAS/mp53 Relative to SAS/neo Tumor Cellsa

\begin{tabular}{llll}
\hline HDR & HDR & MDR & LDR \\
\cline { 3 - 4 } Right after & 9 h later & & \\
\hline Surviving fraction $=0.2$ & & & \\
$1.4 \pm 0.1^{\mathrm{b}}$ & $1.05 \pm 0.1$ & $1.05 \pm 0.1$ & $1.0 \pm 0.1$ \\
\hline
\end{tabular}

aThe ratio of the physical radiation dose of external beams necessary to obtain each end-point in SAS/mp53 tumor cells to that needed to obtain each end-point in SAS/neo tumor cells. ${ }^{b}$ Mean \pm standard error $(n=6)$.

cells relative to SAS/neo tumor cells (Table 3 ). The factors were calculated by comparing the radiation doses to obtain $\mathrm{SF}=0.2$ in SAS/mp53 tumor cells with the doses required in $\mathrm{SAS} /$ neo tumor cells. Following $\gamma$-ray irradiation, the values were decreased in the order of right after HDR $>9 \mathrm{~h}$ after HDR $>$ MDR $>$ LDR because of the apparent recovery from radiation-induced damage in SAS/neo tumor cells, compared with $\mathrm{SAS} / m p 53$ tumor cells that showed little recovery capacity.

Table 4 shows the dose ratios of Q cells relative to total tumor cell populations; these factors were used to compare the radiation doses necessary to obtain the net $\mathrm{MN}$ frequency of 0.1 in Q cells with the doses required in the total tumor cell populations. All the values of the dose ratios were significantly larger than $1.0(\mathrm{P}<0.05)$, and the values increased in the following order of right after HDR $<9 \mathrm{~h}$ after $\mathrm{HDR}<\mathrm{MDR}<\mathrm{LDR}$ in both $\mathrm{SAS} /$ neo and SAS/mp53 tumor cells probably due to a greater recovery capacity in $\mathrm{Q}$ cells than in the total cell population.

\section{Discussion}

PLD is the component of radiation damage that can be modified by post-irradiation conditions [6]. Under ordinary circumstances, PLD causes cell death. Changing cellular growth conditions or the microenvironment around cells influences the expression of PLD or PLDR, and thereby influences sensitivity to radiation. PLDR is favored by conditions that maintain cells without encouraging or allowing them to divide. Conditions found in solid tumors, regions of which may be far from blood vessels and low in glucose and oxygen, have a low extracellular $\mathrm{pH}$, and show high concentrations of cellular waste products, may prevent cells from proliferating and thereby promote the repair of PLD. Extensive studies on PLDR suggest that DNA double-stranded breaks $(d s b s)$ are potentially lethal lesions that can be converted into lethal damage [16]. It was reported that the conversion of potentially lethal lesions into lethal lesions might be a $p 53$-dependent process and that PLDR was proportional to the percentage of radiation-induced DNA $d s b$ s rejoined in $1 \mathrm{~h}$ in the cell lines with a normal $p 53[17,18]$.

Dose rate is one of the principal factors determining the biological consequences of a given absorbed dose. As the dose rate is lowered and the exposure time extended, the biological effect of a given dose is generally reduced. The dose-rate effect, which is very important in radiotherapy, results from the repair of sublethal damage (SLD) that occurs during a long radiation exposure [6]. Incidentally, SLD repair is the opera-
Table 4. Dose-Modifying Factors for Quiescent Relative to Total Tumor Cells ${ }^{a}$ at Net Micronucleus Frequency of 0.1

\begin{tabular}{|c|c|c|c|}
\hline HDR & HDR & MDR & LDR \\
\hline Right after & $9 \mathrm{~h}$ later & & \\
\hline \multicolumn{4}{|l|}{$\mathrm{SAS} /$ пеo } \\
\hline $2.2 \pm 0.2^{\mathrm{b}}$ & $2.2 \pm 0.2$ & $2.4 \pm 0.25$ & $2.45 \pm 0.25$ \\
\hline \multicolumn{4}{|l|}{$\mathrm{SAS} / m p 53$} \\
\hline $1.85 \pm 0.2$ & $1.9 \pm 0.2$ & $1.9 \pm 0.2$ & $1.95 \pm 0.2$ \\
\hline
\end{tabular}

aThe ratio of the dose of radiation necessary to obtain each end-point in the quiescent cell population to that needed to obtain each end-point in the total tumor cell population. ${ }^{b}$ Mean \pm standard error $(n=6)$.

tional term for the increase in cell survival that is observed if a given radiation dose is split into two fractions separated by a time interval. Because continuous LDR may be considered to be an infinite number of infinitely small fractions, the survival curve under these conditions also would be expected to have no shoulder and to be shallower than for a single acute exposure [6]. It was also reported that a normal functioning p53 gene is indispensable for a repair of DNA damage induced under LDR [19, 20]. Further, it was also reported that radiation-induced damage is more easily repaired at the time of low dose-rate than high dose-rate exposure, and as a result, that carcinogenesis due to radiation exposure can be more efficiently suppressed at the time of low dose rate than high dose rate exposure [21].

Following $\gamma$-ray irradiation, concerning whether PLDR after HDR or the repair during MDR or LDR, SAS/neo showed an apparent repair phenomenon in both total and Q-cell populations (Fig. 1 and Table 2). Especially, Q cells in solid tumors with wild-type $p 53$ exhibited greater capacities of the repair than the total cell population, probably due to the intratumor conditions, that is, hypoxic, nutrition-depleted, and low $\mathrm{pH}$ circumstances, where Q cells came into existence [7] (Fig. 2 and Table 2). In contrast, no apparent repair was observed in total or Q-cell populations within p53-mutated tumors (Fig. 2 and Table 2).

Two major pathways for the repair of potentially lethal DNA $d s b s$ exist in mammalian cells. The non-homologous end-joining (NHEJ) pathway is imprecise, error-prone and mutagenic, and mutant cell lines lacking key components of this pathway all exhibit impaired kinetics of DNA $d s b$ repair and exquisite radio-sensitivity $[22,23]$. Homologous recombination (HR) is a more precise (error-free) repair mechanism and is more important for the repair of $d s b$ s in late-S and G2 when a sister chromatid is available for the recombination reaction. Cell lines with defects in HR also exhibit increased radio-sensitivity and decreased fidelity of repair [22, 24].

A cellular safeguard against genetic destabilization is activation of the $p 53$ tumor suppressor protein, which commonly responds to DNA damage signals by inducing apoptosis or regulating the cell cycle including DNA damage repair [22, 25]. As also shown in our previous report [26], the net MN frequencies in SAS/neo tumor cells were lower than those in $\mathrm{SAS} / m p 53$ tumor cells under all conditions $(\mathrm{P}<0.05)$, probably resulting from exclusion of a higher number of radiation- 
induced apoptotic SAS/neo cells than SAS/mp53 cells.

Loss-of-function of wild-type TP53 can result in loss of the G1/S cell-cycle checkpoint and an increase in HR [22, 25]. As $p 53$ seems to interact with RAD51, the absence of normal p53 function is thought to enhance RAD51-mediated DNA pairing activity and HR, due to overexpression of RAD51 out of regulation by normal $p 53[22,25]$. Thus, HR is thought to be a principal mechanism of DNA $d s b$ repair in SAS/mp53 cells. The very small repair capacity of SAS/mp 53 cells in vivo may show that the repair in solid tumors with a mutant $p 53$ is thought to be mainly due to, if anything, the NHEJ rather than HR.

After $\gamma$-ray irradiation, the dose ratios for SAS/mp 53 cells relative to SAS/neo cells showed that SAS/mp53 tumor cells within solid tumors are less radiosensitive than SAS/neo tumor cells (Table 3). This is consistent with reports that tumor cells with a mutant $p 53$ gene were more radioresistant than those with a wild-type $p 53$ gene [26]. Since apparent repair phenomena could be observed in solid tumors with a wild-type p53 gene, the difference in sensitivity between SAS/neo and SAS/mp53 was slightly reduced without significant differences after repair. This finding may be some advantage for controlling malignant tumors, which include significantly more p53-mutated cells than normal tissues [2] in terms of controlling solid tumors as homogeneously as possible.

Nine hours was already shown to be long enough to repair the initial radiation-induced damage after $\gamma$-ray irradiation, and the capacity for PLDR was also shown to be greater in Q cells than in the total cell population [27]. In addition, the reduction in sensitivity caused by a decreasing dose rate under $\gamma$-ray irradiation, which has been ascribed to SLD repair during infinite split-dose irradiation and PLDR during reduced dose-rate irradiation [6], was also shown to be more marked than PLDR during $9 \mathrm{~h}$ after HDR following $\gamma$-ray irradiation and more clearly observed in Q cells than in total cells within solid tumors [28]. The reduction in sensitivity caused by a decreasing dose rate under $\gamma$-ray irradiation, which was more marked than PLDR during the $9 \mathrm{~h}$ after HDR and more clearly observed in Q cells than in total cells [28], produced greater differences in sensitivity between the total and Q cells to $\gamma$-ray irradiation than $9 \mathrm{~h}$ after HDR. This means that requirement to repress the difference in sensitivity between total and Q tumor cells especially in solid tumors with wild-type $p 53$ is getting larger and larger as irradiation dose rate decreases in terms of controlling solid tumors as a whole. In other words, it can be considered that the importance for suppressing the heterogeneity within solid tumors is getting larger as irradiation dose rate decreases. Based on our previous reports concerning the analysis of the characteristics of intratumor Q-cell population in response to conventional antitumor therapy [29], combined treatment with continuous administration of hypoxia-specific cytotoxin like tirapazamine, which can kill both acute and chronic hypoxic tumor cells, and mild temperature hyperthermia, which can release chronic hypoxia and increase drug distribution through increasing blood flow, is considered to be very effective in terms of controlling conventional anticancer therapy-resistant intratumor Q-cell population.

Solid tumors, especially human tumors, are thought to contain a high proportion of $Q$ cells [7]. The presence of these cells is probably due, in part, to a microregional deficiency in the concentrations of oxygen, glucose and other nutritional factors in the tumors caused by poor and heterogeneous tumor vascular supply [7]. This deficiency might promote MN formation in Q tumor cells at 0 Gy (Table 1) [7, 30]. As shown here, Q cells have lower radiosensitivity than P cells in solid tumors in vivo, irrespective of the $p 53$ status of tumor cells (Table 4) [27]. This means that more Q cells survive after radiotherapy than P cells. Consequently, the control of Q cells also has a great impact on the outcome of radiotherapy. Thus, from the viewpoint of the tumor cell-killing effect including intratumor Q-cell control, a treatment modality for enhancing the Q-cell response has to be considered.

\section{Conclusions}

To secure controlling solid tumors as a whole, difference in sensitivity between total and Q tumor cells especially in solid tumors with wild-type $p 53$ has to be suppressed as irradiation dose rate decreases, for instance, through employing combined method for enhancing the response of Q tumor cells.

\section{Acknowledgments}

This study was supported, in part, by a Grant-in-aid for Challenging Exploratory Research (26670556) and a Grant-in-aid for Scientific Research (B) (15H04295) from the Japan Society for the Promotion of Science.

\section{Conflict of Interests}

The authors declare that they have no competing interests.

\section{References}

1. Fei P, El-Deiry WS. P53 and radiation responses. Oncogene. 2003;22(37):5774-5783.

2. Sigal A, Rotter V. Oncogenic mutations of the $\mathrm{p} 53$ tumor suppressor: the demons of the guardian of the genome. Cancer Res. 2000;60(24):6788-6793.

3. Hammond EM, Dorie MJ, Giaccia AJ. ATR/ATM targets are phosphorylated by ATR in response to hypoxia and ATM in response to reoxygenation. J Biol Chem. 2003;278(14):12207-12213.

4. Ahmed RS, Kim RY, Duan J, Meleth S, De Los Santos JF, Fiveash JB. IMRT dose escalation for positive paraaortic lymph nodes in patients with locally advanced cervical cancer while reducing dose to bone marrow and other organs at risk. Int J Radiat Oncol Biol Phys. 2004;60(2):505-512.

5. Wulf J, Haedinger U, Oppitz U, Thiele W, Mueller G, Flentje M. Stereotactic radiotherapy for primary lung cancer and pulmonary metastases: a noninvasive treatment approach in medically inoperable patients. Int J Radiat Oncol Biol Phys. 2004;60(1):186-196. 
6. Hall EL, Giaccia AJ. Fractionated radiation and the doserate effect. In: Hall EJ, Giaccia AJ, editors. Radiobiology for the Radiologist, 7th ed. Philadelphia, Lippincott Williams \& Wilkins; 2012. p. 67-85.

7. Vaupel PW, Kelleher DK. Pathophysiological and vascular characteristics of tumours and their importance for hyperthermia: heterogeneity is the key issue. Int J Hyperthermia. 2010;26(3):211-223.

8. Masunaga S, Ono K. Significance of the response of quiescent cell populations within solid tumors in cancer therapy. J Radiat Res. 2002;43(1):11-25.

9. Jia LQ, Osada M, Ishioka C, Gamo M, Ikawa S, Suzuki $\mathrm{T}$, Shimodaira H, et al. Screening the p53 status of human cell lines using a yeast functional assay. Mol Carcinog. 1997;19(4):243-253.

10. Ohnishi K, Wang X, Takahashi A, Ohnishi T. Contribution of protein kinase $\mathrm{C}$ to p53-dependent WAF1 induction pathway after heat treatment in human glioblastoma cell lines. Exp Cell Res. 1998;238(2):399-406.

11. Toustrup K, Sorensen BS, Alsner J, Overgaard J. Hypoxia gene expression signatures as prognostic and predictive markers in head and neck radiotherapy. Semin Radiat Oncol. 2012;22(2):119-127.

12. Sannigrahi MK, Singh V, Sharma R, Panda NK, Khullar $\mathrm{M}$. Role of autophagy in head and neck cancer and therapeutic resistance. Oral Dis. 2015;21(3):283-291.

13. International Commission on Radiation Units and Measurements. ICRU Report 58: Dose and volume specification for reporting interstitial therapy. Bethesda: ICRU. 1997.

14. Wu H, Hada M, Meador J, Hu X, Rusek A, Cucinotta FA. Induction of micronuclei in human fibroblasts across the Bragg curve of energetic heavy ions. Radiat Res. 2006;166(4):583-589.

15. Ota I, Ohnishi K, Takahashi A, Yane K, Kanata H, Miyahara $\mathrm{H}$, Ohnishi $\mathrm{T}$, et al. Transfection with mutant p53 gene inhibits heat-induced apoptosis in a head and neck cell line of human squamous cell carcinoma. Int J Radiat Oncol Biol Phys. 2000;47(2):495-501.

16. Todd P, Wood JC, Walker JT, Weiss SJ. Lethal, potentially lethal, and nonlethal damage induction by heavy ions in cultured human cells. Radiat Res Suppl. 1985;8:S5-12.

17. Franken NA, van Bree $\mathrm{C}$, ten Cate $\mathrm{R}$, van Oven $\mathrm{CH}$, Haveman J. Importance of TP53 and RB in the repair of potentially lethal damage and induction of color junctions after exposure to ionizing radiation. Radiat Res. 2002;158(6):707-714.

18. Schwartz JL, Rasey J, Wiens L, Jordan R, Russell KJ. Functional inactivation of p53 by HPV-E6 transformation is associated with a reduced expression of radiationinduced potentially lethal damage. Int J Radiat Biol.
1999;75(3):285-291.

19. Kato F, Ootsuyama A, Nomoto S, Kondo S, Norimura T. Threshold effect for teratogenic risk of radiation depends on dose-rate and p53-dependent apoptosis. Int J Radiat Biol. 2001;77(1):13-19.

20. Coleman MA, Yin E, Peterson LE, Nelson D, Sorensen $\mathrm{K}$, Tucker JD, Wyrobek AJ. Low-dose irradiation alters the transcript profiles of human lymphoblastoid cells including genes associated with cytogenetic radioadaptive response. Radiat Res. 2005;164(4 Pt 1):369-382.

21. Tsuruoka C, Blyth BJ, Morioka T, Kaminishi M, Shinagawa M, Shimada Y, Kakinuma S. Sensitive detection of radiation-induced medulloblastomas after acute or protracted gamma-ray exposures in Ptch1 heterozygous mice using a radiation-specific molecular signature. Radiat Res. 2016;186(4):407-414.

22. Houtgraaf JH, Versmissen J, van der Giessen WJ. A concise review of DNA damage checkpoints and repair in mammalian cells. Cardiovasc Revasc Med. 2006;7(3):165-172.

23. Karran P. DNA double strand break repair in mammalian cells. Curr Opin Genet Dev. 2000;10(2):144-150.

24. Hashimoto M, Rao S, Tokuno O, Yamamoto K, Takata M, Takeda S, Utsumi H. DNA-PK: the major target for wortmannin-mediated radiosensitization by the inhibition of DSB repair via NHEJ pathway. J Radiat Res. 2003;44(2):151-159.

25. Horn HF, Vousden KH. Coping with stress: multiple ways to activate p53. Oncogene. 2007;26(9):1306-1316.

26. Masunaga S, Ono K, Takahashi A, Ohnishi T, Kinashi Y, Takagaki M. Radiobiological characteristics of solid tumours depending on the p53 status of the tumour cells, with emphasis on the response of intratumour quiescent cells. Eur J Cancer. 2002;38(5):718-727.

27. Masunaga S, Ono K, Abe M. Potentially lethal damage repair by quiescent cells in murine solid tumors. Int J Radiat Oncol Biol Phys. 1992;22(5):973-978.

28. Masunaga S, Nagata K, Suzuki M, Kashino G, Kinashi $\mathrm{Y}$, Ono K. Inhibition of repair of radiation-induced damage by mild temperature hyperthermia, referring to the effect on quiescent cell populations. Radiat Med. 2007;25(8):417-425.

29. Sumiyoshi K, Strebel FR, Rowe RW, Bull JM. The effect of whole-body hyperthermia combined with 'metronomic' chemotherapy on rat mammary adenocarcinoma metastases. Int J Hyperthermia. 2003;19(2):103-118.

30. Bindra RS, Schaffer PJ, Meng A, Woo J, Maseide K, Roth $\mathrm{ME}$, Lizardi $\mathrm{P}$, et al. Alterations in DNA repair gene expression under hypoxia: elucidating the mechanisms of hypoxia-induced genetic instability. Ann N Y Acad Sci. 2005;1059:184-195. 